encontra consideravelmente atenuada." (Lebrun 3 p. 458-459).

6. Esta cisão entre razão e paixão, no entanto, não foi obra exclusiva do estoicismo, mas antes circulou por várias escolas antigas, fossem idealistas ou materialistas. Michey Meyer procura traçar sua gênese a partir da dialética de Platão que elabora um saber racional sobre o pathos para enfrentar as questões da ética e da política. "Para falar das paixões como Platão é preciso estar além, muito além do obstáculo que elas constituem. É na ordem da razão que podemos discorrer sobre a paixão. Mas uma questão de fundo surge imediatamente: a quem se aplica esta ideia da paixão, se uns nada sabem das paixões e outros estão muito além para delas falar? Não são ambos, os homens ordinários e os filósofos, estrangeiros na paixão, uns por tê-las sem pensar e outros, pelo contrário, por pensar e não tê-las mais? Não estão ambos mergulhados na mesma indiferença? Que sentido há em falar disso que uns não podem entender e outros não têm mais com que se preocupar?” (Meyer 4, p. 25).

\section{O ELOGIO DA TOLERÂNCIA EM PIERRE BAYLE}

Maria Cecília Almeida*

Resumo: A obra de Pierre Bayle colaborou decisivamente para a formação do discurso filosófico sobre o conceito de tolerância, noção central nas sociedades modernas. Os escritos de Bayle foram essenciais para a disseminação daquela idéia pelos philosophes no século XVIII. Uma das principais teses defendidas por Bayle é que a liberdade de consciência e de opinião deve ser garantida aos indivíduos. O Estado não deve perseguir por motivos religiosos e não deve haver violência quando se trate de opiniões que não geram perigo para a ordem pública. A liberdade de consciência tem por conseqüência uma tolerância irrestrita que deve se estender a todas as confissões religiosas e até mesmo aos ateus. O propósito deste texto é analisar alguns argumentos de Bayle na defesa da tolerância, sobretudo no Commentaire Philosophique, com a intenção de evidenciar a novidade do tratamento do autor, que por meio de metáforas e inversões, estabelece a tolerância como algo importante e benéfico para a sociedade política.

Palavras-chave: liberdade de consciência, lei, tolerância, religião.

Nos dias atuais, a tolerância é posta juridicamente como "sustentáculo" dos direitos humanos (e da democracia) ${ }^{1}$. Se a sua presença em uma sociedade democrática não é mais questionada, e tida cada vez mais como desejável, permanece entretanto a dificuldade em esclarecer as articulações entre aquelas noções. Pode ser útil para esse propósito um estudo sobre a história do conceito de tolerância, tendo em vista a ligação entre tolerância e os direitos do homem e a prática de sua defesa em um 
mesmo momento histórico. Neste contexto, a obra de Pierre Bayle (16471706) revela-se um campo privilegiado de reflexão.

Um texto essencial que procura estabelecer uma defesa da tolerância é o Commentaire philosophique (1686), que reúne e consolida elementos centrais de textos anteriores do autor: Pensées diverses sur la comète (1682), Nouvelles lettres critiques (1685), e Ce que c'est que la France toute catholique sous le règne de Louis le Grand (1686). A preocupação primordial é estabelecer e justificar a tolerância religiosa, embora idéias acerca do tema estejam disseminadas em toda obra de Bayle, inclusive no Dictionnaire Historique Critique (1696). O Commentaire philosophique foi publicado na Holanda, sob pseudônimo. Nele nota-se um visível engajamento ${ }^{2}$ por parte de seu autor, já que poucos se opunham frontalmente à intolerância religiosa. O propósito deste texto é apresentar algumas idéias importantes na defesa da tolerância de Pierre Bayle, concentradas sobretudo no Commentaire philosophique, procurando apontar a originalidade deste pensador na construção daquele conceito.

O leitor moderno encontra raciocínios bastante familiares quando se depara com a construção desta noção em Bayle, de modo que nem sempre é fácil perceber o que sua filosofia tem de novo ou de revolucionário. Para isso é preciso ter em mente que a intolerância era a regra, e a tolerância, a exceção. Pierre Bayle foi uma figura-chave na "revolução intelectual" operada pela defesa da tolerância, por meio da qual se operou uma "inversão do pensável" (Cf. Bayle, 6, introdução, p. 17). Depois de seus escritos, a tolerância deixa de ser uma resignada aceitação do mal inevitável, ou uma mera atitude psicológica, e passa a ser uma atitude positiva e uma postura política (cf. Vienne, 31, p. 126). É exatamente esta concepção da tolerância como virtude e ao mesmo tempo como exigência da vida política que será explorada e divulgada no Século das Luzes.

Os pensadores do Iluminismo certamente consideraram os escritos de Pierre Bayle como referência obrigatória no domínio da filosofia, da moral e da política. Voltaire em suas Cartas Filosóficas faz um aberto elogio à obra de Bayle. De acordo com o autor das Cartas, este último apesar de ser perseguido é filósofo exemplar (Cf. Voltaire, 33, "Filósofo", pp. 195-196). Além disso, o verbete Tolerância da Enciclopédia também revela que o século XVIII seguiu de perto a doutrina da tolerância de Bayle. Nele, o autor, Jean Edme Romilly, sustenta uma defesa da tolerância e utiliza argumentos presentes em textos de Bayle. Ao longo do artigo, é possível observar a referência quase textual aos escritos deste último, especialmente à tese sobre os direitos da consciência errante $(\mathrm{Cf}$. D’Alembert e Diderot, 13, "Tolérance").

No entanto, atualmente, estudos sobre a obra do autor do Dicionário histórico e crítico parecem cada vez mais raros. Um dos motivos desta negligência pode ser o próprio estilo de Bayle, escritor prolífico, mas que não produziu uma obra muito sistematizada. Se, por um lado, isso tende a afastar as pretensões de análise filosófica "pura", por outro, torna o seu exame ainda mais interessante e desafiador, pois para compreendêlo é preciso muitas vezes ultrapassar as fronteiras da filosofia, e adentrar campos como o da literatura e o da história.

Além disso, o próprio estilo de Bayle impõe dificuldades: a sua escrita não produz um único caminho, mas uma rede sutil e complexa de teses e justificações, por meio de digressões, anedotas e ironias. As formas eleitas por Bayle para veicular seu pensamento também não são muito convencionais: a filosofia não se faz apenas nos tratados, nas sumas e discursos, mas em panfletos, textos jornalísticos de uma revista, observações em um dicionário. Se não é específica e sistemática, ela se torna essencialmente crítica (cf. Bayle, 6, introdução, p. 10). Ao apresentar suas idéias, o autor adota inúmeras metáforas, histórias, exemplos, repetições, discursos e diálogos fictícios. Esta variedade, tanto na forma quanto no 
conteúdo, juntamente com a preocupação sempre presente de pesar os prós e contras de cada argumento, podem ser parte da mensagem. Na exposição sobre a liberdade de consciência, em especial, parece correto supor que o meio faz parte da mensagem. A pluralidade de pontos de vista é expressa igualmente por vários modos (Cf. Laursen, 22, p. 198.).

A maior parte da presente análise será feita a partir do Commentaire philosophique, obra dedicada integralmente à refutação da interpretação literal das Escrituras, nas palavras “Obriga-os a entrar”, interpretação esta que era um dos principais argumentos utilizados pelos perseguidores para constranger fiéis de outras religiões e para justificar a coerção. A defesa do ideal da tolerância também perpassa vários dos verbetes do Dicionário histórico e crítico, obra mais célebre e de maturidade do autor. Nela, constata-se que certos artigos são meros pretextos para externar a opinião do filósofo sobre os mais variados assuntos. O autor faz isso nas inúmeras notas de rodapé contidas nesta obra, que por vezes ultrapassam em larga medida o espaço dedicado à exposição dos verbetes.

O objetivo inicial do Dicionário seria apontar os erros cometidos por outros escritores, filósofos e historiadores, ou seja, a intenção seria a de restabelecer a verdade dos fatos. Esta empresa recebeu críticas de figuras importantes do cenário intelectual da época, como Leibniz, que entendia que uma compilação de erros ou de controvérsias entre eruditos "seria menos útil do que tediosa" (Bahr, 8, p. xvii.) e propôs que Bayle reorientasse o projeto num sentido positivo. Este passou então a, além de denunciar os erros, compilar as verdades, e ainda considerar outras versões ou opiniões sobre uma mesma questão, sempre com um sistema de referências cuidadoso para que os leitores pudessem reconhecer as fontes (cf. idem, 8, p. xvii). No Dicionário, Bayle dificilmente perde a ocasião de criticar Moreri, autor do dicionário mais famoso da época, mas que traz inúmeros fatos e relatos que carecem de precisão (cf. Hazard, 16, p.
88). Além disso, é nesse texto que Bayle exerce em toda a sua veemência um traço essencial de seu pensamento: a crítica. As notas do Dicionário refletem a posição do autor acerca dos mais variados assuntos e trata de idéias que a posteridade absorverá, como o ceticismo, a tolerância religiosa, o rigor na crítica e a notação bibliográfica cuidadosa.

\section{A elaboração de um conceito}

Um dos grandes temas do pensamento bayliano é o elogio da tolerância, noção considerada um dever tanto do poder político como dos indivíduos. Muitos dos escritos e polêmicas de Bayle tratam deste tema com argumentos que são bastante ousados para a sua época. Isso se dá, grosso modo, por dois motivos: em primeiro lugar, porque, diferentemente de muitos defensores da tolerância, Bayle não se limita a discutir quais seitas deveriam ser toleradas, ou que tipos de ritos deveriam ser permitidos. Este autor se destaca exatamente por pretender fundar a tolerância filosoficamente, e por isso essa noção será bastante ampla. Esta visão é confirmada pelo estudioso Jean-Michel Gros:

o Commentaire philosophique é uma das argumentações mais novas e mais audaciosas de seu tempo para justificar a tolerância civil. Ao fundamentá-la sobre uma definição de liberdade de consciência, é uma resposta teórica a uma das maiores tragédias de nossa história: a revogação do Edito de Nantes (Bayle, 6, introdução, p. 10).

Nesse sentido, o trabalho de Bayle reflete uma preocupação amplamente difundida em alguns círculos de sua época: a intolerância religiosa, tema comum à filosofia de John Locke e Spinoza entre outros. Embora tenham sido publicados depois do Commentaire, o Ensaio sobre 
o entendimento humano (1690), e mesmo as Cartas sobre a tolerância (1689), de Locke, apresentam diversos argumentos filosóficos e políticos em defesa da tolerância, destacando a falibilidade e as limitações do conhecimento humano, como a variação das palavras pelo tempo e as dificuldades ligadas ao significado de muitos termos empregados na linguagem religiosa ortodoxa (cf. Marshall, 25, p. 470 e Locke, 24, IV, XIX, §§ 5-8 e XX, §18). Na Carta sobre a tolerância, Locke rejeita a idéia segundo a qual se poderia constranger alguém a crer visando o seu bem, ou seja, com o intuito de mostrar o verdadeiro caminho da salvação. Para Locke, assim como para Bayle, a crença não pode ser imposta coercitivamente. A convicção interior é algo imprescindível para a verdadeira fé, que, segundo Locke, é a única que é agradável a Deus. A vontade é inútil para interferir neste processo, pois assim como nossas percepções e idéias, a fé não depende de nossa vontade ${ }^{3}$.

No entanto, diferentemente de Locke, ao construir a sua fundamentação da tolerância, Bayle critica com veemência os excessos cometidos pela Igreja romana na perseguição aos huguenotes, e não exclui nenhuma seita; antes, aceita-as todas porque não reclama apenas a tolerância, mas a liberdade de consciência. Por isso, não aceita o argumento comumente utilizado por alguns protestantes, segundo o qual não seriam os católicos que deteriam o direito de perseguir, mas os protestantes. Bayle rejeita este argumento de reciprocidade e por isso mesmo vai além de seu tempo quando valoriza uma república que concede liberdade crítica para todos - a "república das letras"4, que não teme a pluralidade de crenças (cf. Jenkinson, 18, pp. 311-312). Assim, Bayle defende uma tolerância radical, que não exclui confissões e que inclui pagãos e ateus. Poucos pensadores da época compartilhavam deste ponto de vista. Mesmo Locke, um dos grandes teóricos da tolerância no século XVII, excluía ateus e católicos quando se tratava de tolerância religiosa.
Em segundo lugar, no tratamento dado à noção de tolerância, Bayle tenta inverter o sentido negativo que esta palavra tinha nos séculos XVI e XVII, ao sustentar que esta tem um valor intrínseco, fundado na razão. No século XVI a palavra tolerância mantém o máximo de sua carga negativa (que existe, de certo modo, até hoje): tolerar então era sofrer, suportar pacientemente um mal inevitável, como se se tratasse de uma doença ou de uma infecção (cf. Cottret, 11, p. 5). Só se tolerava o que não se podia impedir. Também era comum que a tolerância designasse uma atitude de leniência frente ao mal ou à falta. Indicava uma espécie de conivência ou aceitação de um erro. Quem era "tolerante" poderia ser acusado de indiferença religiosa, ou mesmo de mentalidade irreligiosa (cf. Bobbio, 10, p. 150), quando não de subversão (cf. Ashcraft, 1, p. 532). Por outro lado, a intolerância designava uma virtude, uma espécie de integridade moral ou firmeza para com os preceitos morais, algo próximo da noção de austeridade.

Para efetuar esta inversão, para que a tolerância deixasse de ser vício e passasse a ser virtude, Bayle rejeita argumentos e teses que eram correntes no século XVII e que julgavam ser a tolerância algo nocivo ao corpo político. Ainda, inverte também a concepção que existia na época com relação à novidade em si mesma. $\mathrm{O}$ conceito de inovação, o innovare, a idéia de mudança, ao longo dos séculos XVI e XVII era visto como potencialmente pernicioso, sobretudo em matéria de religião, como confirma Mario Turchetti:

No domínio religioso (...) a idéia de renovação não tem uma recepção muito favorável. (...) Em geral, a introdução da novidade, na liturgia, no cerimonial e sobretudo na doutrina, atrai a reprovação geral, porque o novum é assimilado ao vitiosum, ao ambitiosum, ao inane, desde os tempos antigos (Cf. Turchetti, 30, p. 12). 
Ora, o empreendimento de Bayle é justamente o de modificar a interpretação literal de uma passagem do Evangelho, e afirmar que o novo sentido, que permitirá uma ação tolerante por parte do Estado e dos indivíduos, não é nocivo, mas, ao contrário, benéfico. Em várias passagens do Commentaire philosophique é evidente o esforço do autor no sentido de mostrar que as novidades - mesmo em religião - não são más por si mesmas, embora seja essa a idéia corrente: "ainda que uma explicação da Escritura seja razoável, se ela é nova, eles dizem que ela não vale nada, que ela vem muito tarde e que há prescrição contra" (Bayle, 6, I, 8, pp. 157-158).

Diferentemente da maioria dos homens de seu tempo, Bayle vê a novidade como algo bom, tanto no direito quanto na religião, sobretudo quando é conforme aos princípios da razão: "não se deve jamais recusar esclarecer-se com aqueles que têm alguma coisa de novo a dizer. Pois como saber se aquilo não é melhor do que o que até aqui cremos de boa fé?" (Bayle, 6, Bayle, II, 5, p. 253). E um pouco adiante: “a experiência nos ensina que houve novidades em matéria de religião que foram boas e santas" (Bayle, 6, Bayle, II, 5, p. 259).

Parte da resistência à ideia do novum está associada à doutrina que entendia que a mudança de religião acarretaria a mudança do governo ou do Estado ${ }^{5}$. Assim, também no domínio político, a novidade e a mudança eram sempre vistas com desconfiança. E por isso mesmo poucos se aventuravam a fazê-lo. Aquele que tentasse introduzir novidades poderia sofrer algum tipo de acusação (cf. Turchetti, 30, p. 12. $)^{6}$. Bayle procura inverter esse sentido essencialmente negativo da mudança e da novidade, apelando sobretudo à experiência histórica e ao caráter precário de nosso conhecimento:

Será que depois de tantas experiências devemos crer hoje que é impossível que alguém nos ensine coisas novas?
Isso mostra que toda lei que exclua novos esclarecimentos ou o progresso dos conhecimentos humanos e divinos é violenta. Onde estaríamos se há dois ou três mil anos esta lei tivesse sido implementada? (Bayle, 6, II, 5, p. 254).

Essa defesa da novidade é essencial em sua estratégia, pois para estabelecer a tolerância como valor positivo é necessário que se abandone uma certa interpretação da passagem do Evangelho, mas isso não basta. É preciso ainda que se aceitem certas idéias novas sob um prisma diferente. Isso é fundamental para o estabelecimento não apenas da idéia de tolerância, mas igualmente da liberdade de consciência e de sua noção de consciência errante.

Bayle prepara o caminho para atingir um dos objetivos declarados do Commentaire philosophique: refutar a velha interpretação literal agostiniana da parábola contida no Evangelho de Lucas (Lucas, 14: 23). Nesta passagem, o dono da casa prepara um banquete para seus convidados, que se escusam. Diante disso, o dono diz ao criado que traga os pobres, os aleijados, os coxos e os cegos que encontrar nas ruas e nas praças da cidade. O criado informa ao senhor que seguiu suas ordens, mas que ainda há lugares à mesa, ao que o senhor diz ao servo: "vai pelos caminhos e trilhas e obriga as pessoas a entrarem, para que a minha casa fique repleta". O compelle intrare erroneamente interpretado será o leitmotiv de toda exposição de Bayle. O sentido da parábola retomada por Santo Agostinho para reconduzir os donatistas à Igreja da África foi recuperado por católicos entre os séculos XVI e XVII para justificar a coerção contra os protestantes (cf. Hazard, 16, p. 86).

O Commentaire philosophique de Bayle procura, assim, refutar a interpretação literal de uma passagem da Escritura que fundamentava a intolerância, e para isso será obrigado a discutir os vários argumentos que tentavam justificar igualmente esta idéia. $\mathrm{O}$ autor deixa clara esta intenção 
logo no início da obra, que busca provar, "por várias razões demonstrativas, que não há nada mais abominável do que fazer conversões pela coerção. E onde se refuta todos os sofismas dos conversores sobre a coerção e a defesa que Santo Agostinho fez das perseguições" (Bayle, 6, DP, p. 45). Para isso utiliza argumentos racionais, filosóficos, lógicos, epistemológicos, teológicos, políticos, jurídicos e morais em seu texto.

O texto do Commentaire é precedido por um "discurso preliminar". Nele, o autor "se apresentará". Bayle não assume a autoria desta obra, mas apresenta seu heterônimo como um certo escritor inglês, Jean Fox de Bruggs ${ }^{7}$. Este explica que procederá à refutação do sentido literal da parábola contida em Lucas a pedido de um francês refugiado na Inglaterra. O "inglês" esclarece as razões pelas quais aceitou o trabalho. Ele teria duas qualidades essenciais a esta tarefa: uma aversão extrema às perseguições e também o costume de procurar as boas razões das coisas ${ }^{8}$. Estas características estarão de fato presentes no decorrer do texto. Não raras vezes Bayle indigna-se, exclama, e até injuria ${ }^{9}$, sobretudo quando relata as violências perpetradas contra os huguenotes na França. Ao mesmo tempo, não deixa de analisar as razões de cada argumento, que por vezes se subdivide em muitos outros, todos minuciosamente examinados, e alguns insistentemente retomados, como se o autor compusesse variações sobre um tema (cf. Laursen, 22, p. 198), buscando estabelecer, em última instância, as teses verdadeiras, ou ao menos, as mais prováveis.

Depois da "apresentação" do autor, o texto procura expor o seu objetivo, bem como esclarecer a etimologia que será ali utilizada. Bayle apresenta o seu intento como um "Comentário filosófico sobre as palavras da parábola nupcial, das quais os conversores, isto é, os perseguidores, abusam" (Bayle, 6, D.P., p. 48). Trata-se então de uma obra sobre o abuso, sobre o excesso e o equívoco na interpretação da palavra da Escritura, o que, por sua vez, geraria mais excesso. Esse é um tópico que aparecerá com freqüência ao longo da argumentação bayliana.
O próximo passo é estabelecer os termos que serão utilizados no debate. Bayle estabelecerá que o conversor, o desonesto e o perseguidor são a mesma coisa. Explica ele que assim como aconteceu com as palavras tirano e sofista, que designavam apenas rei e filósofo, ocorreu uma grande modificação, e mesmo uma inversão em seu sentido:

Eis a imagem ingênua da destinação do nome de conversor : ele devia originalmente significar uma alma realmente zelosa pela verdade e por esclarecer os errantes; mas ela não significará mais que um charlatão, um patife, uma ladrão, um saqueador de lares, uma alma sem piedade, sem humanidade, sem eqüidade, um homem que procura expiar, às custas do sofrimento alheio, sua falta de pudor no passado e no futuro e todos os seus desregramentos. Ou se consideramos que todos esses atributos não convêm precisamente a cada conversor, diremos com menos palavras qual será doravante o sentido justo e legítimo desse termo. Ele significará um monstro metade padre e metade dragão, e que, como o Centauro da fábula que reunia em uma mesma pessoa o homem e o cavalo, une em um só agente os diferentes personagens do missionário que disputa e do soldado atormenta um pobre corpo e que pilha uma casa (Bayle, 6, D.P., p. 49)

Os conversores são representados de maneira forte e dramática. A palavra conversor, longe de guardar o sentido original, que designava um ser pio e caridoso, agora se refere a um monstro "metade padre e metade dragão", que comete injustiças e violências e que procura expiar as próprias faltas às custas de outrem. É contra este ser monstruoso que Bayle lança pesadas críticas.

O Commentaire philosophique insiste em que a interpretação coerente da Escritura aponta para uma coexistência pacífica entre as religiões. É justamente o oposto do que é pregado pelos perseguidores, 
que afirmam a legitimidade da perseguição, baseada na interpretação de Santo Agostinho: o compelle intrare ou "obriga-os a entrar". Ao atacar esta construção teológico-política que justificava a intolerância, a tentativa de Bayle é de deslocar a questão, mudar o terreno do debate. O autor procura fazer um comentário de um "gênero novo", uma elaboração filosófica que pretende refutar à exaustão o significado atribuído sobretudo pelo Catolicismo às palavras de Santo Agostinho. Segundo Bayle, é preciso embaraçar um pouco os perseguidores, "tirá-los de seus lugares comuns e propor-lhes dificuldades sobre as quais ainda não tiveram tempo de inventar escapatórias" (Bayle, 6, D.P., p. 50). É necessário que a argumentação seja filosófica e não puramente teológica, pois polêmicas exclusivamente teológicas sobre a interpretação de certas passagens da Escritura se arrastavam por séculos, sem que houvesse vencedores incontestáveis ${ }^{10}$.

Ao investigar qual é o fundamento da perseguição, Bayle analisa se aqueles que se arrogam o direito de perseguir realmente o possuem legitimamente. Apesar de julgar viver em um século esclarecido, a sua constatação é que "a polidez universal do século não pode fazer nada contra a ferocidade do papismo" (Bayle, 6, D.P., p. 52). Além de insinuar um certo pessimismo em relação à história, a sua conclusão será a de que tanto os católicos quanto os protestantes não têm o direito de perseguir: "eu não quero que isso nos leve a nenhuma represália contra os papistas; não, eu detesto estas imaginações; eu desejo somente que eles não adquiram a força de executar sobre nós o que eles sabem fazer”(Bayle, 6, D.P., p. 55).

É nesse ponto que Bayle se destaca da tradição, sobretudo da posição de outros defensores da tolerância protestantes, pois a tese segundo a qual o Estado deveria ser laico, ou mesmo que não deveria haver uma religião de Estado era altamente controversa em seu tempo, dado confirmado por Mario Turchetti :
As exigências de uma unidade confessional são tão vivas e imperiosas para os reformados quanto para os católicos. É um princípio evangélico (Paulo aos Efésios 4:4-6), ao qual o teólogo, qualquer que seja sua confissão, não pode renunciar (Turchetti, 30, p. 28).

Uma das teses políticas usadas largamente entre os séculos XVI e XVII afirma que antes de ser um assunto que só diz respeito à consciência de cada um, a tolerância tem a ver com a função que a religião deve desempenhar no Estado. Segundo esta opinião, o reforço da uniformidade religiosa é uma característica fundamental do Estado unitário. Este argumento é fundamental até mesmo para a revogação do Edito de Nantes. É expresso pelo adágio “cujus regio, hujus religio", ou "a religião é de quem é a região", ou ainda na sua versão francesa "un roi, une foi, une loi". Se um Estado é tanto melhor quanto menor seja o número de religiões que ele abrigue, não se trata mais de uma questão da glória de Deus ou da salvação do próximo, mas simplesmente do interesse vital que uma sociedade tenha no consenso religioso de seus membros. Assim, se há uma religião oficial, a lealdade política de todo dissidente religioso passa a ser duvidosa.

Bayle é claramente contrário à tese da uniformidade religiosa. Segundo ele, a adoção de uma religião única será sempre fonte de conflito no Estado, pois em raras sociedades existe apenas uma crença religiosa. Além disso, dificilmente se estabelecerá claramente que seita deve ter precedência sobre as outras. Ora, é justamente essa discussão que os controversistas católicos querem evitar. Retomando argumentos de Santo Agostinho, freqüentemente justificavam o fato dos protestantes não poderem deter os mesmos direitos que os católicos, porque estes fariam parte de uma igreja fundada por Jesus Cristo e pelos apóstolos, enquanto que a nova religião não teria nem duzentos anos, e portanto, careceria de uma "autoridade legítima" (Bayle, 6, D.P., p. 56). Esse argumento não 
fazia dos protestantes heréticos, mas apenas cismáticos; denominando-os assim, haveria um pretenso direito da Igreja sobre aqueles, assim como o direito de uma mãe sobre os filhos que estão dela afastados.

A resposta de Bayle a este argumento é contundente. Em primeiro lugar, afirma que os protestantes não podem ser comparados a crianças, e portanto, é inócuo o velho jargão que afirma que só há uma Igreja verdadeira e mãe, da qual os protestantes são apenas filhos rebeldes. Não há, desse modo, nenhum direito daquela de os castigar, pois isso implicaria o direito dos protestantes poderem fazer o mesmo, pois, quando se trata da prerrogativa de perseguir, é preciso que todos se submetam à mesma regra. Bayle subverte inteiramente a justificação católica, fazendo da "Igrejamãe", uma "infame meretriz":

A pretensão dos protestantes é que a Igreja romana, bem longe de ser esta Esposa de Jesus Cristo, que é a mãe dos verdadeiros cristãos, seja apenas uma infame meretriz, que se apodera da casa, assistida por uma tropa de rufiões, de bandidos, e de pessoas de saco e de corda; que perseguiu o pai, a mãe e as crianças; que estrangulou essas crianças o máximo que pode; e que forçou os outros a reconhecêla como senhora legítima, ou os obrigou a viver exilados. Esses filhos exilados que não podem viver sob a vergonha de fingir reconhecer por mãe uma meretriz, que expulsou sua mãe, e matou uma parte de seus irmãos, estes são os protestantes. (Bayle, 6, D.P., p. 58).

Sob essa perspectiva, Bayle observa que os protestantes teriam tanta razão em perseguir quanto os católicos, pois é da ordem das coisas humanas que se vingue uma mãe indignamente banida de sua casa por uma meretriz com toda energia. Eles não precisariam aí ter qualquer indulgência (cf. Bayle, 6, D.P., p. 59). Esta metáfora cumpre pelo menos três funções: em primeiro lugar, ao apresentar os argumentos católicos e protestantes,
Bayle afirma que nada justifica o direito de perseguir. Em segundo lugar, pelo princípio da reciprocidade, estabelece logicamente um patamar de igualdade entre as seitas adversárias: se um tem o direito de perseguição, é preciso mostrar com bons argumentos porque o outro não o possui. Este princípio da reciprocidade será um tema repetido constantemente em diversas passagens do autor. Para que haja uma discussão sobre o assunto, é preciso ao menos que se reconheça que as regras devem ser aplicadas reciprocamente ${ }^{11}$, isto é, elas devem valer igualmente para todas as religiões. Nota-se o amplo esforço do autor ao tentar mostrar que nada justifica a precedência de uma seita sobre outra. Por fim, mostra que muito tempo foi perdido nestas disputas, e que o recurso à Escritura e à autoridade pouco ou nada contribui para o estabelecimento de uma posição segura.

Segundo Bayle, o que impede o estabelecimento de alguma solução para as disputas teológicas - e mesmo de um diálogo - é o fato de todas as religiões terem a pretensão de ser as únicas verdadeiras e de quererem impor tal presunção a todas as outras. Isso acarretaria a necessidade de conversão de todos aqueles que estão "em erro", isto é, que professem outras religiões, muitas vezes com recurso justificado à violência. $\mathrm{O}$ autor apresenta bem essa idéia em um discurso fictício de um representante da Igreja Católica primitiva:

De resto, senhor, não se segue que tenhamos o direito de constranger (...): falamos em nome da verdade, e por isso nos é permitido infligir violência às pessoas. Mas as falsas religiões não possuem este privilégio: o que elas fazem é de uma crueldade bárbara; o que nós fazemos é completamente divino e uma santa caridade (Bayle, 6, II, 9, p. 165).

Nesse sentido, a confrontação de duas religiões só pode produzir o endurecimento dos crentes em sua fé, além de gerar mais violência. As discussões e disputas teológicas que recaem frequentemente em círculos 
viciosos não conseguiram esclarecer os homens ou demonstrar uma única verdade. Daí a necessidade de Bayle em recorrer à filosofia, à razão e à crítica para fundamentar a sua noção da tolerância.

\section{Uma tolerância radical}

Como reforço lógico das idéias anteriores, Bayle apresenta a noção de diversidade religiosa como algo útil e benéfico às sociedades políticas. Se a tolerância é desejável em suas premissas, ela o é ainda mais nas suas conseqüências. $\mathrm{O}$ autor tenta mostrar que, ao contrário do que se pensava na época, os princípios da tolerância não introduzem conflito no Estado. Ao contrário, "é a não tolerância que causa todas as desordens imputadas falsamente à tolerância" (Bayle, 6, D.P., p. 73). Para Bayle, a multiplicidade de religiões não é um mal, antes ela é fonte de prosperidade (Cf. Bayle, 4, "Hospital”, (F)). É importante reconhecer que o autor não se volta apenas contra os métodos ou a crueldade dos castigos que são fruto da intolerância. Uma grande preocupação que se reflete em seu texto é sem dúvida a justificação e as conseqüências de tais métodos, o que requer uma discussão que ultrapasse os limites da teologia, pois esta não oferece uma explicação suficiente para a coerção. Segundo Bayle, a Escritura é frequentemente mal interpretada ou admite mais de uma interpretação em algumas passagens. Portanto, é preciso buscar argumentos na razão natural, na filosofia e ainda apelar à história e à experiência.

Por esta razão, o filósofo trará à cena o paganismo nos Pensées diverses sur la comète e também na Continuation des pensées diverses, para mostrar que a tolerância não é nociva às sociedades. De acordo com o autor, o paganismo era dividido em uma infinidade de seitas. Havia cultos muito diferentes e os principais deuses de um país não eram os mesmos em outros. Entretanto, jamais houve guerra de religião entre os pagãos: "em todo lugar muita calma e tranqüilidade, e por quê? Porque uns toleravam os ritos dos outros" (Bayle, 6, D.P., p. 73). O autor cita ainda o exemplo dos filósofos atenienses que discordavam em muitas coisas, inclusive sobre o que consistia a Providência ou o soberano bem. No entanto, os magistrados permitiam a sua convivência, e a república não sofria nenhuma alteração por esta diversidade de sentimentos. Mas se tivessem usado da coerção, a comunidade teria entrado em conflito. Isso leva Bayle a concluir: "portanto, a tolerância é fonte de paz, e a intolerância, fonte de confusão e desordem" (Bayle, 6, D.P., p. 73-74).

A filosofia de Bayle, mas especialmente o Commentaire philosophique constrói um plano teórico que, ao refutar as razões dos perseguidores, funda positivamente a tolerância, sob uma perspectiva racional e ainda da sinceridade moral e religiosa. Seu programa será radical, com a recusa total da coerção e a extensão da tolerância inclusive ao ateu e ao herege. A tolerância está para a sociedade política tal como a polifonia para a música: apesar da diversidade de cultos, e muitas vezes das oposições existentes, o resultado final é de harmonia e concórdia.

Ao apresentar a tolerância como um imperativo para o qual não pode haver exceções, Bayle, diferentemente da maior parte dos defensores da tolerância de seu tempo, não excluirá católicos, protestantes e nem mesmo ateus: "é preciso tudo ou nada. Não se pode ter boas razões para tolerar uma seita se elas não são boas o suficiente para tolerar uma outra" (Bayle, 6, II, 7, p. 272). O único limite da tolerância são atos que se choquem com a conservação da sociedade política, pois isso implicaria em última instância uma desobediência às leis civis.

Se todas as crenças devem ser igualmente toleradas quando compatíveis com a ordem pública, e se a revelação não é modo seguro de reconhecer a via para a verdade, o ateu não deve ser excluído 
deste esquema. A tese central de Bayle é a de que os ateus podem agir corretamente sem recorrer à religião, pois são seres dotados de razão. Ao elaborar esta conclusão, Bayle gera outra - e importante - inversão: o ateu, considerado herege e monstro sacrílego deixará de ser um perigo social, ao mesmo tempo em que um cristão deixará de ser por isso mesmo um cidadão modelo. Antonio Carlos dos Santos sintetiza bem esta mudança:

Bayle inverte, completamente, a percepção sobre o ateu e o cristão: o ateu, como não acredita em penas ou recompensas após a morte, identifica-se muito mais com a ação virtuosa do que o cristão, que age de forma interesseira, preocupado com uma contrapartida futura (Santos, 29, p. 256).

Segundo Bayle, averdadeiravirtudeprescinde dereconhecimentos ou recompensas. O ateu, embora não creia em Deus, pode guiar-se pelo critério de utilidade mas também pela honestidade. Por isso, ele pode ser mais virtuoso que o cristão, pois faria o bem de forma desinteressada:

a razão ditou aos antigos sábios que seria preciso fazer o bem por amor ao próprio bem, e que a virtude deveria ter ela mesma como recompensa, e que só era próprio de um homem mau se abster do mal pelo medo do castigo (Bayle, 5, § 178).

A razão sem o conhecimento de Deus pode conhecer o que é honesto e bom. Desta forma, o ateu não representa nenhum perigo para a sociedade. Além disso, mesmo um homem destituído de fé pode ser sensível à glória do mundo. Diferentemente de John Locke, por exemplo, para Bayle o ateu é capaz de respeitar os contratos. As más conseqüências de suas ações são sensíveis neste mundo e não em outro. Bayle afirma que muitas vezes o móbil da ação humana é a estima interior dos outros homens ${ }^{12}$. E por isso há a possibilidade de uma sociedade formada por ateus. Por não crerem na providência divina, nem na imortalidade da alma, uma república de ateus teria mais confiança nas leis promulgadas e isso favoreceria a condição de uma vida socialmente digna.

Grande parte da construção teórica de Bayle visa legitimar certos direitos ligados à liberdade de consciência e de crítica. $\mathrm{O}$ autor entende ser essencial o direito de assembléia, e mais ainda o direito de "raciocinar modestamente a favor de sua crença e contra a doutrina oposta"(Bayle, 6, II, V, p. 252). A crítica, como "arte de julgar" é essencial para evitar dogmatismos e para discernir uma verdade, seja ela religiosa ou não. É este princípio que deve ser perseguido pelos governantes, não a unidade religiosa, algo impossível de se conseguir, mas uma abertura perpétua à crítica (cf. Jenkinson, 18, p. 317).

É notável em Bayle esse exercício constante da crítica, a preocupação em pesar os prós e os contras de cada argumento, o que geralmente leva ao questionamento ou à anulação dos principais dogmas religiosos. É preciso exercitar a razão, uma vez que a intolerância será freqüentemente associada à preguiça crítica ou à ignorância. Por isso, Bayle confere à crítica um papel especialmente importante, algo que chega a se confundir com seu estilo, o que é confirmado por Koselleck:

A crítica torna-se a instância judicativa que distingue a razão, que faz avançar constantemente o processo dos prós e contras. Após o enorme trabalho de Bayle, o conceito de crítica estará indissociavelmente ligado ao conceito de razão (Koselleck, 19, p. 96).

Bayle entende como ideal uma sociedade que não tema o pluralismo de religiões e que valorize a liberdade da crítica. $\mathrm{O}$ fundamento desta liberdade será metafísico, pois inscrito nas consciências, é parte da natureza humana. Assim como Hobbes ou Grotius, Bayle deriva os seus princípios políticos da natureza do homem e da natureza do Estado. Diante 
da fragilidade dos enunciados jurídicos da tolerância, Bayle esforçou-se para produzir um comentário de um gênero novo, de tipo filosófico baseado em pressupostos racionais e sobretudo críticos. A tentativa de fundar a liberdade de consciência em pressupostos universais também se explica tendo em vista a história da França, com as inúmeras promulgações e revogações de decretos e editos que ora concediam, ora retiravam direitos.

Mas como garantir esta tolerância radical, tão laboriosamente elaborada em sua obra? Parece claro que Bayle não acredita que nenhuma religião, qualquer que seja, possa reconhecer tais direitos. Esta função só poderá ser exercida pelo poder político, pois essas liberdades não podem ser garantidas independentemente do Estado. Embora o Estado possa ser um perseguidor, e a França sob Luís XIV o era de fato, para o autor o poder político é a principal garantia da liberdade. A soberania é condição essencial para a efetividade de certos direitos dos indivíduos. É o Estado que promove a harmonia de opiniões dissonantes, é ele que, apesar de imperfeito, poderá assegurar a desejada paz e a polifonia de crenças. Em Bayle, a liberdade e os direitos da consciência, fundados numa ordem metafísica, mas também justificados pela perspectiva da teologia, da história e da crítica não podem igualmente abrir mão da via da política.

\section{L'ÉLOGE DE LA TOLÉRANCE CHEZ PIERRE BAYLE}

Résumé: L'œuvre de Pierre Bayle a collaboré à formation du discours philosophique sur le concept de tolérance, notion centrale dans les sociétés modernes. Les textes de Bayle ont été essentiels pour cette idée, répandue par les philosophes du XVIIIème siècle. Bayle soutient l'idée de la liberté de conscience et d'opinion qui doit être assuré aux hommes. L'état ne doit pas persécuter pour raisons religieuses et la violence doit être interdite quand ce sont en cause des opinions qui ne troublent pas l'ordre publique. La liberté de conscience a pour conséquence une tolérance étendue qui peut se répandre par toutes les confessions religieuses e même aux athées. Ce texte a pour but l'exposition d'arguments de Bayle dans son plaidoyer de la tolérance, concentrés au Commentaire philosophique, afin de faire une analyse de ce concept avec l'intention de mettre au premier plan la nouveauté de la pensée du philosophe, que parmi métaphores et inversions, établit la tolérance comme importante et bénéfique à la société politique.

Mots-clés : liberté de conscience, loi, tolérance, religion.

\section{REFERÊNCIAS BIBLIOGRÁFICAS:}

1. ASHCRAFT, R. La politique revolutionnaire et les Deux traités de governement de Locke. Paris: Presses Universitaires de France, 1995.

2. BAHR, Fernando. Introdução. In: Bayle, P. Diccionario Histórico y Crítico. Buenos Aires: Facultad de Filosofia y Letras Universidad de Buenos Aires, 2003.

3. BAYLE, P. Avis important aux réfugiez sur leur prochain retour en France [...] par Monsieur C.L.A.A.P.D.P. Amsterdam, J. Le Censeur, 1690.

4. Dictionnaire historique et critique. [Reprod. em fac-símile]. 5 ed. Amsterdam, Leyde, La Haye, Utrecht: [s.n.], 1740. 4 v.

5._Pensées Diverses sur la Comète. Paris, Librairie E. Droz, 1939. (Disponível em: <http://www.lib.uchicago.edu/efts/ARTFL/projects/dicos/BAYLE/>.)

6. De la tolérance: Commentaire philosophique sur ces paroles de Jésus-Christ «Contrains-les d'entrer». Ed. Jean-Michel Gros. Paris, AgoraPresses pocket, 1992.

7. Political Writings. Ed. Sally L. Jenkinson. Cambridge University Press, 2000.

8. Diccionario Histórico y Crítico. Introd. e trad. Fernando Bahr. Buenos 
Aires: Facultad de Filosofia y Letras Universidad de Buenos Aires, 2003.

9. BOBBIO, N. A Era dos Direitos. Rio de Janeiro, Campus, 1992

10. Elogio da Serenidade. São Paulo, Ed. Unesp, 2000.

11. COTTRET, Bernard. De l'édit de Nantes à la Glourieuse Révolution - concorde, liberté de conscience, tolérance. La naissance de l'idée de tolérance (16601689). Publications de l'Université de Rouen, n²60, pp. 3-28, 1999.

12. CREPPELL, Ingrid. "Locke on Toleration: The Transformation of Constraint". In: Political Theory, Vol. 24, n02 (May, 1996), pp. 200-240.

13. D'ALEMBERT, Jean Le Rond e DIDEROT, Denis (eds.). Encyclopédie ou dictionnaire raisonée des sciences, des arts et des métiers, par une société de gens de lettres. University of Chicago: ARTFL Encyclopédie Project (Spring 2011 Edition), Robert Morrissey (ed), http://encyclopedie.uchicago.edu/.

14. DELUMEAU, Jean. Nascimento e afirmação da reforma. Tradução: João Pedro Mendes. São Paulo: Pioneira, 1989

15. HABERMAS J., De la tolérance religieuse aux droits culturels, Cités 2003/1, n 13, p. $151-170$

16. HAZARD, Paul. Crise da consciência européia. Lisboa, Edições Cosmos, 1948.

17. ISRAEL, Jonathan. Enlightenment Contested - philosophy, modernity, and the emancipation of man (1670-1752). Oxford University Press, 2006.

18. JENKINSON, Sally L. Two concepts of tolerance: or why Bayle is not Locke. The Journal of Political Philosophy. Volume 4, no 4, 1996, pp. 302-321.

19. KOSELLECK, Reinhart. Crítica e crise. Rio de Janeiro, EDUERJ, Contraponto, 1999.

20. LABROUSSE, Elisabeth. "Note à propos de la conception de la tolérance au XVIIIle siécle”. In: Notes sur Bayle. Paris, Vrin, 1987.

21. Pierre Bayle. Hétérodoxie et Rigorisme. Paris, Albin Michel, 1996.

22. LAURSEN, John Christian. Baylean liberalism: Tolerance requires nontolerance. In: Laursen, John Christian e Nederman, Cary J. (eds.). Beyond the persecuting society: Religious toleration before the Enlightenment. University of Pensilvania Press, 1997.

23. LOCKE, John. A Letter Concerning Toleration. New Haven and London, Yale University Press, 2003.

24. An Essay concerning Human Understanding. Ed. Peter H. Nidditch. Oxford, Clarendon Press, 1988.
25. MARSHALL, John. John Locke, Toleration and Early Enlightenment Culture. Cambridge, Cambridge University Press, 2006.

26. MORI, Gianluca. Bayle philosophe. Paris, Honoré Champinon, 1999.

27. PIQUET, Nicolas e Waterlot, Ghislain (ed.). Tolérance et réforme-Elements pour une généalogie du concept de tolerance. Paris, L’Harmattan, 1999.

28. RETAT, Pierre. Le Dictionnaire de Bayle et la lutte philosophique au XVIIIe. Siècle. Paris: Société d'Édition "Les Belles Lettres", 1971.

29. SANTOS, Antonio Carlos dos. A via de mão dupla. Tolerância e política em Montesquieu. Ijuí: Ed. Unijuí; Sergipe: EDUFS, 2006.

30. TURCHETTI, Mario. Réforme \& tolérance, un binôme polysémique. In : Piqué, N, e Waterlot, Ghislain. Tolérance et Réforme - Elements pour une généalogie du concept de tolerance. Paris, L'Harmattan, 1999.

31. VIENNE, Jean-Michel. La tolérance, de Spinoza à Locke. Études Littéraires. Volume $32 \mathrm{n}^{\circ} \mathrm{s} 1-2,2000$.

32. VOLTAIRE. Traité sur la Tolérance. In: Ouvres Philosophiques. Paris, Larousse, s/d. 33. . Dicionário Filosófico. São Paulo. Abril Cultural, 1978. (Col. “Os Pensadores)

\section{NOTAS}

1. A Declaração de Princípios sobre a Tolerância, aprovada pela Conferência Geral da UNESCO de 16 de novembro de 1995, estabelece no seu artigo $1^{\circ}$, item 1.3: "A tolerância é o sustentáculo dos direitos humanos, do pluralismo (inclusive o pluralismo cultural), da democracia e do Estado de Direito. Implica a rejeição do dogmatismo e do absolutismo e fortalece as normas enunciadas nos instrumentos internacionais relativos aos direitos humanos".

2. Defensor infatigável da tolerância religiosa e da liberdade de consciência, a vida desse filósofo foi de certo modo marcada pela religião: nascido em 1647, filho de um pastor calvinista, converteu-se ao catolicismo em 1669 e estudou filosofia no colégio dos Jesuítas de Toulouse. Após ter concluído o curso, retorna à Igreja reformada. Em 1675, torna-se professor na Academia Calvinista de Sedan, mas deixa o seu posto pouco antes da Academia ser fechada por Luís XIV, para exilar-se na Holanda em 1681. Em 1685 teve seu irmão, Jacob Bayle, aprisionado e morto por razões religiosas. Todo o período vivido na Holanda é de grande engajamento intelectual. Bayle é professor para prover o seu sustento, mas dedica grande parte de seu tempo à 
função de polemista e de jornalista. Em 1684 é um dos fundadores de Nouvelles de la république des lettres, uma das publicações literárias e filosóficas mais influentes de seu tempo. No entanto, seus escritos heterodoxos tornaram-no um homem malvisto mesmo pelos protestantes e, em 1693, Bayle perde a sua cátedra em Rotterdam, sem explicações formais e com alguma humilhação pública. Apesar disso, continuará a escrever incansavelmente até o fim de sua vida, em 1706. (Cf. Bayle, 7, pp. xlii-xlix). Sobre a vida de Bayle, vale conferir Labrousse, E. Pierre Bayle: du pays de Foix à la cité d'Erasme. Paris, Albin Michel, 1963, como também a breve descrição de Mori disponível em http://www.lett.unipmn.it/ mori/bayle/biogr.html, e ainda a recente biografia escrita por Hubert Bost, Pierre Bayle, Paris, Fayard, 2006.

3. Para Locke, "o cuidado das almas não pode pertencer ao magistrado civil, porque seu poder consiste apenas na força exterior. Mas a religião verdadeira e salvadora consiste na persuasão interna (inward persuasion) da mente, sem o que nada pode ser aceitável para Deus. E tal é a natureza do entendimento, que não pode ser forçado a crer em algo por uma força exterior. Confisco de bens, aprisionamento, torturas, nada dessa natureza pode surtir qualquer eficácia para fazer os homens mudarem o julgamento interno que eles têm das coisas". (Locke, 23, p. 219).

4. "A "república das letras" era republicana. Crucialmente, era o ethos definido pelos processos de descoberta, comunicação e discussão entre os eruditos nesses anos centrados precisamente nas "virtudes" de uma "república": nos deveres da cidadania, na participação virtuosa, na liberdade e na igualdade entre os seus cidadãos". (Marshall, 25, p. 507).

5. Bayle entende que esta ideia era um lugar comum, repetida por ignorantes. No entanto, não deixa de refutá-la. (Cf. Bayle, 6, II, 6, p. 258).

6. Ainda nesse sentido, Turchetti cita carta de Étienne Pasquier à M. de Fonssonme, de 1560, na qual aquele afirma “j'abhorreray le changement de l'Estat, qui advient ordinairement par le changement des Religions". (Turchetti, 30, p. 13).

7. Jean-Michel Gros esclarece que o nome escolhido por Bayle esconde um jogo de palavras que remete a George Fox, quaker que foi defensor da tolerância, e a David Joris, fundador de uma seita anabatista nos Países Baixos e que foi submetido a uma ativa perseguição. (Cf. Bayle, 6, pp. 43-4).

8. Segundo Bayle, "conseguir fazer isso é prestar um grande serviço à boa causa, e mesmo a todo mundo" (Cf. Bayle, 6, p. 47).

9. Como quando se refere à Igreja romana como "megera e prostituta", e não como mãe de seus fiéis. (Cf. Bayle, 6, p. 58).
10. Segundo J.M. Gros, Bayle insiste em um comentário de natureza filosófica justamente porque depois de dois séculos de polêmicas houve uma perda geral de credibilidade do discurso teológico. (Cf. Bayle, 6, Introdução., p. 20).

11. Sobre este tema, afirma Habermas : «En cela précurseur de Kant, Bayle préconise une adoption réciproque des perspectives et nous incite à universaliser les « idées » à la lumière desquelles nous jugeons la nature de l'action humaine » (Habermas, 15, p. 153).

12. Ainda nos Pensées Diverses, Bayle afirma que aqueles que sustentam que a alma morre com o corpo são por princípio mais gente de bem do que outros, porque teriam um interesse particular em não adquirir uma má reputação - e dá o exemplo do usurário, que por não poder depreciar o negócio, é o mais exato dentre todos os homens a cumprir o que promete e nos termos que promete (cf. Bayle, 5, § 179). 